\title{
Magnetic Response of Heavy Metal Pollution in Soil of Urban Street Greenbelts
}

\author{
Junhui Zhang, ${ }^{1, *}$, Qing Lin ${ }^{1}$, Bin Liu ${ }^{1}$, Yunjiu Guan ${ }^{1}$, Yaxin Wang ${ }^{1}$, Dongxing Li ${ }^{1}$, \\ Xionghui Zhou ${ }^{1}$, Xiuli Kang ${ }^{1}$
}

\author{
${ }^{1}$ College of Geography and Environment, Baoji University of Arts and Sciences, Baoji 721013, China \\ ${ }^{2}$ Shaanxi Key Laboratory of Disasters Monitoring and Mechanism Simulation, \\ Baoji University of Arts and Sciences, Baoji 721013, China
}

Received: 27 April 2021

Accepted: 17 August 2021

\begin{abstract}
The magnetic characteristics and heavy metal elements of surface soil samples in Baoji urban street greenbelts were systematically analyzed in order to explore the feasibility of using magnetic parameters to indicate heavy metal pollution in urban street greenbelts soil. The results of the study showed that ferromagnetic minerals with low-coercivity and coarse magnetic grains dominated magnetic properties of the samples. The average values of low-frequency magnetic susceptibility $\left(\chi_{\mathrm{ff}}\right)$ was $200.65 \times 10^{-8} \mathrm{~m}^{3} / \mathrm{kg}$, which was much higher than the background value. The spatial variation of magnetic mineral content was remarkable, with high levels observed in heavy traffic areas and industrial gathering areas, and low content in areas heavily covered by short vegetation, which was basically consistent delineated by pollution load index (PLI). Magnetic parameters $\chi_{\mathrm{If}}$, saturated isothermal remanent magnetization (SIRM) and soft remanent magnetization (SOFT) can be used as the effective indicators for monitoring heavy metals pollution in soil of urban street greenbelts.
\end{abstract}

Keywords: magnetic response, heavy metal pollution, urban street greenbelts, environmental magnetism, pollution load index

\section{Introduction}

Urban soil pollution has serious impacts on the environment, and common pollutants mainly include heavy metals and organic pollutants originating from anthropogenic activities such as industrial production, automobile exhaust, fossil fuel combustion and residential waste. Waseem et al. [1] reviewed the heavy

e-mail: bwlzjh@126.com metal contamination in several areas of Pakistan over the past few years and found that the presence of trace heavy metals in the soil can cause serious problems to organisms, and the ubiquitous bioavailability of these heavy metal can result in bioaccumulation in the food chain which especially can be highly dangerous to human health. Accordingly, understanding the type, distribution, and degree of contamination of pollutants are critical to development of effective protocols for harm reduction [2-4]. It is feasible to monitor urban pollution via studying topsoil because pollutants 
generated from human activities exist mainly in the $\mathrm{O}$ and A layers of soil, which exhibit distinct characteristics from natural soil [5-7]. Iron sphere particles produced by combustion contain high concentration of heavy metals, and elements such $\mathrm{As} \mathrm{Cu}, \mathrm{As}, \mathrm{Zn}, \mathrm{Pb}$ and $\mathrm{Cd}$ produced by combustion always appear with iron oxides, so that magnetic particles are strong adsorbents and carriers of heavy metals [8]. Many researchers have found that there is a strong correlation between the concentration of heavy metals and magnetic parameters through studying the soil near factories, the soil near roads and other sediments contaminated by various heavy metals $[9,10]$. Traditional methods of geochemical studies usually take a long time and involve complicated procedures and high costs, while environmental magnetism provides a simple, economical, rapid and non-destructive method that is useful to soil pollution monitoring [11-13]. Analysis of magnetic susceptibility of soil shows that some magnetic minerals in soil are produced by human activities such as vehicle emissions, and that magnetic susceptibility of topsoil is higher than that of deep soil $[14,15]$. When compared with the soil of new communities that are affected by human factors for a short period, the soil of old cities has stronger magnetism, suggesting that magnetic minerals in the soil can persist for a long time and do not easily break down [4, 16]. Petrovsky et al. [17] analyzed the correlation between magnetic susceptibility and heavy metal content and found that these two factors were linearly correlated, indicating that differences in magnetic content can be used to distinguish the heavy metal content caused by human activities. By studying soils in northwestern Iran, Ayoubi et al. [18] found that strong positive correlations between $\chi_{\text {If }}$ and $\mathrm{Fe}, \mathrm{Mn}, \mathrm{Zn}, \mathrm{Ni}, \mathrm{Co}$, and $\mathrm{Cr}$ in all soil samples, and multiple linear regression between metal contents and $\chi_{\text {If }}$ showed that $\mathrm{Ni}, \mathrm{Zn}, \mathrm{Mn}$, and Co could explain $77 \%$ of the total variance in $\chi_{\mathrm{lf}}$ in the study area. Zhong et al. [19] studied the magnetic signature of heavy metal contamination in urban soil from steel industrial city and showed that the soil $\chi_{\text {If }}$ and SIRM values are significantly correlated with the contents of metals ( $\mathrm{Fe}, \mathrm{Pb}, \mathrm{Zn}, \mathrm{Cu}$, and $\mathrm{Cr}$ ), which indicates that $\chi_{\text {If }}$ and SIRM could be served as better indicators for the pollution of heavy metals in the urban topsoil. In addition, Oudeika [20] dealt with the determination of the environmental pollution in Denizli Organized Industrial Zone and its surroundings, and found that the $\chi_{\text {If }}$ and heavy metals distribution showed similar locations, giving a sign of the liberation of industrial wastes into the surrounding areas. Overall, many studies showed that magnetic parameters including $\chi_{\text {If }}$ SIRM and SOFT are significantly correlated with heavy metals content, which provides a theoretical basis for magnetic parameters indicating soil heavy metal pollution [21-24]. Correlation analysis between PLI and magnetic parameters has been utilized to establish the soil heavy metal pollution level standard based on environmental magnetic parameters. The level standard is further used to delineate highly polluted areas, especially industrial and traffic areas [25-28]. Previous studies focused on magnetic responses of soil to pollution from the perspective of entire cities; however, only a few studies have investigated the soil of greenbelts, which are the main carrier of pollution from urban streets, to investigate magnetic properties, heavy metals distributions and their correlation. The characteristics of soil pollution in greenbelts can reveal changes in urban traffic and environments, as well as show distinct pollution levels caused by different effects of vegetation cover. The analysis of pollution characteristics of greenbelt soil can provide solutions to urban environmental pollution, especially street traffic pollution.

Baoji located in the west of Guanzhong plain, $180 \mathrm{~km}$ away from Xi'an. Heavy industry is the main economy of Baoji, including automotive manufacturing, non-ferrous metal smelting, special equipment manufacturing and rail transportation equipment manufacturing, with coal as the main source of energy. Industrial activity and transportation have brought great pressure on the environment. In this study we selected soil of the urban greenbelts of Baoji as the research object, and used a combination of environmental magnetism and heavy metal characteristics to analyze the content, type and particle size of soil magnetic minerals in the urban greenbelts of Baoji. We also explored the magnetic characteristics and spatial distribution of heavy metals and their correlation to establish a soil heavy metal pollution level standard for urban greenbelts based on environmental magnetic parameters.

\section{Materials and Methods}

\section{Sampling}

In this study, we selected greenbelt soil from the main traffic streets of Baoji (Gaoxin Avenue, Binhe Road, Gongyuan Road, Jiangtan Road, Baofu Road, Jinger Road, Dongfeng Road and Daqing Road). Dry soil samples were taken under fine weather with low humidity in November of 2017. The samples at each sampling point were collected and mixed to give comprehensive soil samples using the fivepoint sampling method, after which they were sealed in sample bags. A total of 33 representative topsoil samples were obtained using this preparation method (Fig. 1).Soil samples from the northern suburbs of Baoji $\left(\mathrm{S}_{0}\right)$ were collected as background samples.

\section{Magnetic Measurements}

The samples were further air dried naturally in the lab, after which the litter, gravel, plant roots and other debris were removed. The samples were then ground 


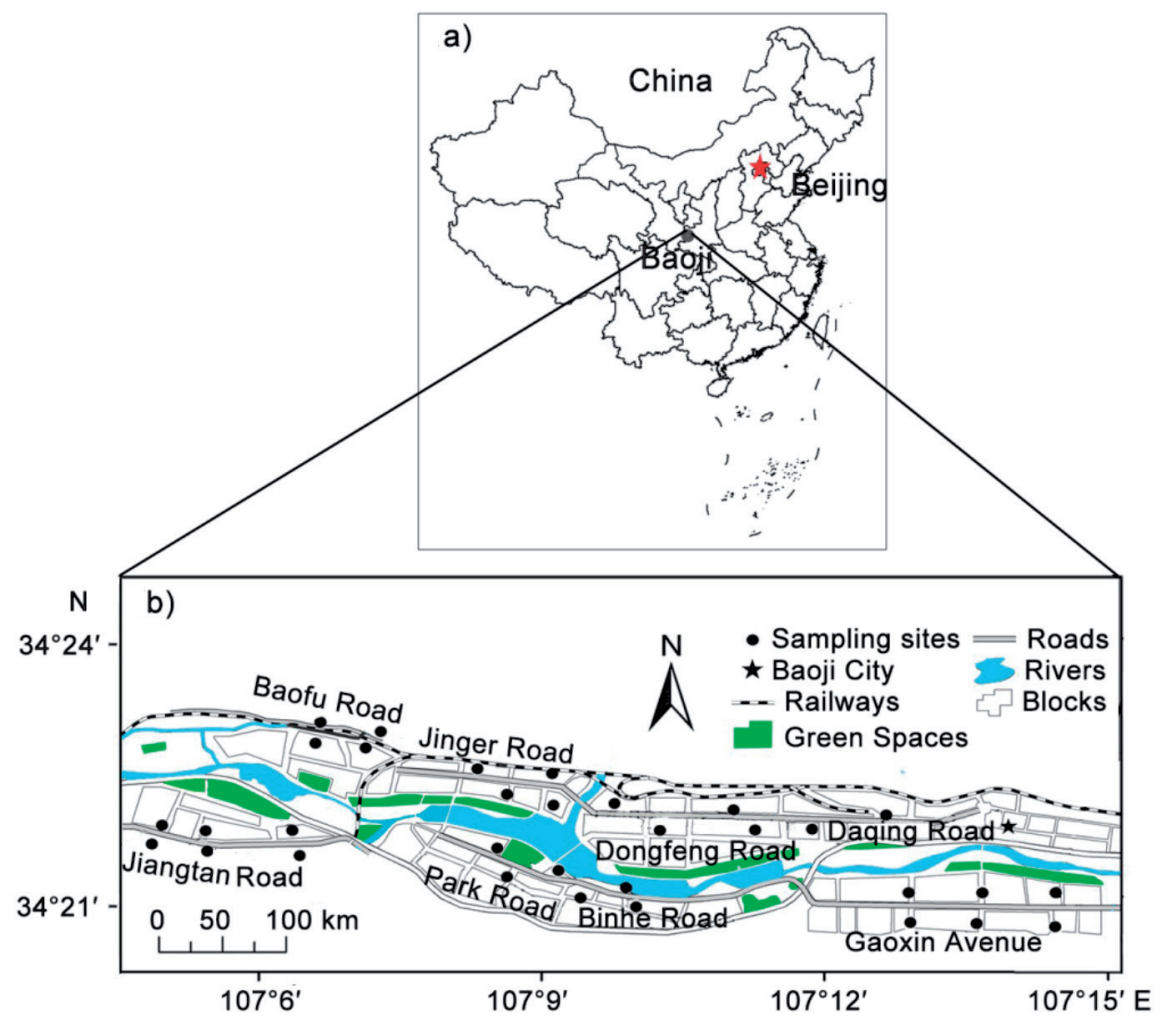

Fig. 1. Location of Baoji in China a). Sampling location of soil in Baoji b).

and filtered through a 100 mesh nylon sieve. About $5 \mathrm{~g}$ of sample were then taken and put into a non-magnetic cube sample box of $8 \mathrm{~cm}^{3}$ for magnetic parameter measurement.

A MS2B magnetic susceptibility meter (Bartington Inc, UK) was used to measure low frequency (470 Hz) magnetic susceptibility $\left(\chi_{1 f}\right)$ and high frequency $(4700 \mathrm{~Hz})$ magnetic susceptibility $\left(\chi_{\mathrm{hf}}\right)$ of samples. Frequency susceptibility $\left(\chi_{\mathrm{fd}}\right)$ was then calculated using the formula $\chi_{\mathrm{fd}} \%=\left[\left(\chi_{\mathrm{lf}}-\chi_{\mathrm{hf}}\right) \chi_{\mathrm{lf}}\right] \times 100$. An ACSD-2000T demagnetization device and a JR-6A dual-speed spinner magnetometer were used to measure non-hysteresis remanent magnetization (ARM). The measured peak magnetic field was $100 \mathrm{mT}$ with a current field of $0.05 \mathrm{mT}$. $\chi_{\mathrm{ARM}}$ was then calculated accordingly. An ASCIM-10-30 pulse magnetizing apparatus was used to sequentially apply forward magnetic fields of 300 $\mathrm{mT}$ and $1 \mathrm{~T}$ and reverse magnetic fields of $20 \mathrm{mT}$ and $300 \mathrm{mT}$ to all samples. A JR-6A dual-speed spinner magnetometer was used to measure isothermal remanent magnetization (IRM), wherein the IRM obtained at 1T field strength was referred to as the SIRM. Hard remanent magnetization (HIRM) was calculated as $\mathrm{HIRM}=\left(\mathrm{SIRM}+\mathrm{IRM}_{-300}\right) / 2, \mathrm{SOFT}=\left(\mathrm{SIRM}-\mathrm{IRM}_{-20}\right) / 2$, $\mathrm{S}_{\text {-ratio }}=\left(\mathrm{IRM}_{-300} / \mathrm{SIRM}\right) \times 100 . \mathrm{A}$ FORC chart of representative samples was generated using a VSM3902 variable gradient magnetometer (Lake Shore, USA). The maximum field strength applied was 1T. The measurements were conducted in the Institute of Earth Environment, Chinese Academy of Science.

\section{Elemental Analysis}

$0.2 \mathrm{~g}$ of air-dried and sieved sample were weighed into digestion tubes, after which nitric acidhydrofluoric acid-perchloric acid (2:1:1) were added sequentially for digestion. The digestion solution was subsequently transferred to a $50 \mathrm{~mL}$ colorimetric tube for measurement of $\mathrm{Pb}, \mathrm{Cu}, \mathrm{Cd}$ and $\mathrm{Zn}$ using ICP-MS (Agilent Inc., Japan). The experiments were measured at the Shaanxi Key Laboratory of Disasters Monitoring and Mechanism Simulation, Baoji University of Arts and Sciences.

\section{Pollution Load Index}

PLI reveals the contribution of various heavy metals to environmental pollution and their spatial trends [29]. The formula is:

$$
\begin{gathered}
C F_{\mathrm{i}}=C_{\mathrm{i}} / \mathrm{C}_{0 \mathrm{i}} \\
P L I=\sqrt[n]{C F_{1} \times C F_{2} \times \ldots \times C F_{n}}
\end{gathered}
$$

where $C F$ is the highest pollution coefficient of element $\mathrm{i} ; C_{\mathrm{i}}(\mathrm{mg} / \mathrm{kg})$ is the content of element $i$ in the actual sample, and $C_{0 \mathrm{i}}(\mathrm{mg} / \mathrm{kg})$ is the background value. In this study, the background value of soil elements in Shaanxi Province was selected, and $n$ was the type of element involved in the evaluation. 
Table 1. Basic magnetic parameters of street greenbelt soil in Baoji City.

\begin{tabular}{|c|c|c|c|c|c|c|c|}
\hline & $\begin{array}{l}\chi_{\mathrm{If}} \times 10^{-8} \\
/ \mathrm{m}^{3} \cdot \mathrm{kg}^{-1}\end{array}$ & $\begin{array}{c}\chi_{\mathrm{fd}} \\
1 \%\end{array}$ & $\begin{array}{l}\mathrm{SIRM} \times 10^{-5} \\
/ \mathrm{Am}^{2} \cdot \mathrm{kg}^{-1}\end{array}$ & $\begin{array}{c}\chi_{\text {ARM }} \times 10^{-8} \\
/ \mathrm{m}^{3} \cdot \mathrm{kg}^{-1}\end{array}$ & $\begin{array}{c}\mathrm{SOFT} \times 10^{-5} \\
/ \mathrm{Am}^{2} \cdot \mathrm{kg}^{-1}\end{array}$ & $\begin{array}{l}\mathrm{HIRM} \times 10^{-5} \\
/ \mathrm{Am}^{2} \cdot \mathrm{kg}^{-1}\end{array}$ & S-ratio \\
\hline Max & 390.38 & 7.58 & 5625.99 & 965.78 & 3577.86 & 161.50 & 0.99 \\
\hline Min & 96.18 & 0.94 & 881.15 & 245.95 & 588.75 & 6.78 & 0.88 \\
\hline Mean & 200.65 & 3.77 & 2068.38 & 563.43 & 1368.95 & 68.87 & 0.93 \\
\hline Background & 33.45 & 2.25 & 102.32 & 103.54 & 153.41 & 26.52 & 0.92 \\
\hline
\end{tabular}

\section{Results and Discussion}

\section{Magnetic Mineral Concentration}

The magnetic susceptibility $(\chi)$ indicates the ability of a substance to be magnetized by an external magnetic field. This value is usually used to estimate the content of ferrimagnetic minerals, which are affected by the type, particle size and content of magnetic minerals in the sample $[30,31]$. The soil sample $\chi_{1 \mathrm{f}}$ in the study area ranged from $96.18 \times 10^{-8}$ to $390 \times 10^{-8} \mathrm{~m}^{3} / \mathrm{kg}$ with an average of $200.65 \times 10^{-8} \mathrm{~m}^{3} / \mathrm{kg}$. SIRM reveals the enrichment of single domain (SD) magnetic particles and multi domain (MD) magnetic particles in samples, and is not affected by paramagnetic minerals [32, 33]. The SIRM of the soil samples in this study ranged from $881.15 \times 10^{-5}$ to $5629.99 \times 10^{-5} \mathrm{Am}^{2} / \mathrm{kg}$ with an average value of $2068.38 \times 10^{-5} \mathrm{Am}^{2} / \mathrm{kg}$. $\chi_{\text {ARM }}$ mainly indicates the concentration of stable single-domain ferrimagnetic particles [34]. The soil sample $\chi_{\text {ARM }}$ in the study area ranged from $245.95 \times 10^{-8} \mathrm{~m}^{3} / \mathrm{kg}$ to $965.78 \times 10^{-8}$ $\mathrm{m}^{3} / \mathrm{kg}$, with an average value of $563.43 \times 10^{-8} \mathrm{~m}^{3} / \mathrm{kg}^{-1}$. As shown in Table 1, the mean values of $\chi_{\text {If }}$, SIRM and $\chi_{\mathrm{ARM}}$ of the soil samples in the study area are higher than those of the background samples, indicating that the concentrations of soil magnetic minerals in the greenbelts of Baoji are relatively high.

\section{Magnetic Mineral Type}

SOFT mainly reveals the low coercivity magnetic particle content of multidomain and single domain boundary ranges, which closely reveals the concentration of magnetite [35]. The soil samples SOFT in the study area ranged from $588.75 \times 10^{-5}$ to $3577.86 \times 10^{-5} \mathrm{Am}^{2} / \mathrm{kg}$ with average values of $1368.95 \times 10^{-5} \mathrm{Am}^{2} / \mathrm{kg}$. HIRM primarily reflects the content of incomplete antiferromagnetic minerals (hematite, goethite) in the sample [31]. The HIRM of soil samples in the study area varied from $6.78 \times 10^{-5}$ to $161.5 \times 10^{-5} \mathrm{Am}^{2} / \mathrm{kg}$, with a mean value of $68.87 \times 10^{-5} \mathrm{Am}^{2} \mathrm{~kg}^{-1} \cdot S_{-}$ratio is an indicator of the relative content of low coercivity ferrimagnetic minerals (magnetite, maghemite) and high coercivity incomplete antiferromagnetic minerals (hematite, goethite) in the sample. An $S_{-}{ }_{\text {ratio }}$ value close to 1 indicates that the main magnetic bearing mineral in the sample is low coercivity ferrimagnetic mineral [36]. As shown in Table 1, the mean value of $S_{\text {-ratio }}$ is 0.93 , which is close to 1 , while the mean value of SOFT $\left(1368.95 \times 10^{-5} \mathrm{Am}^{2} / \mathrm{kg}\right)$ was much higher than that of HIRM $\left(68.87 \times 10^{-5} \mathrm{Am}^{2} / \mathrm{kg}\right)$. This mean value indicates that the soil of the greenbelts of Baoji are dominated by low coercivity magnetite and contain incomplete antiferromagnetic minerals.

IRM primarily reveals the content of ferrimagnetic minerals and incomplete antiferromagnetic minerals in the samples [37]. As shown in Fig. 2a), the IRM curve of representative soil samples under maximum field strength of $1 \mathrm{~T}$ showed that the sample reached about 94\% saturation under the $300 \mathrm{mT}$ field, indicating that the sample subjected to a small portion of high coercivity hematite was not fully saturated, but that the main magnetic bearing minerals were low coercivity magnetite and maghemite. Remanence coercivity $\left(B_{\mathrm{cr}}\right)$
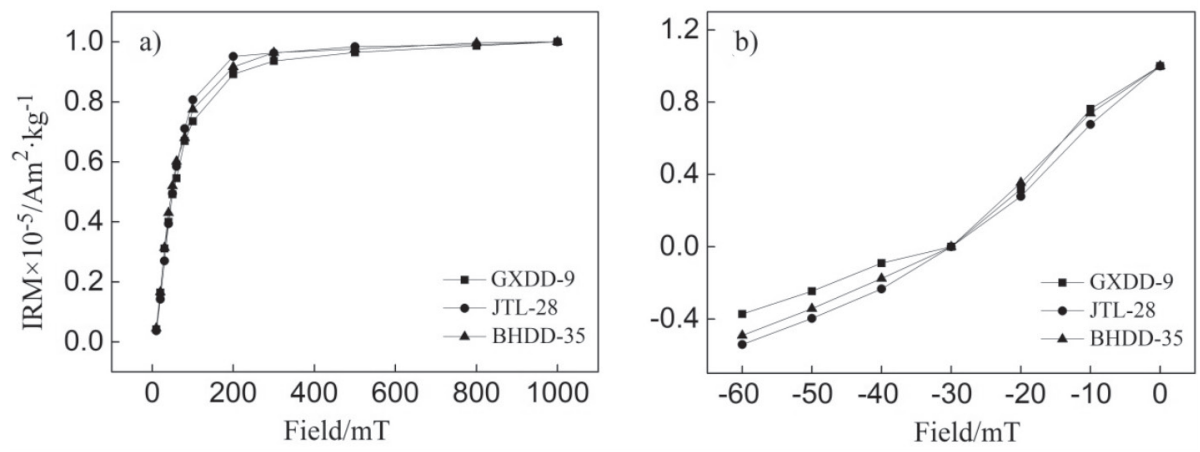

Fig. 2. a) IRM acquisition curves of representative samples. b) Back-field demagnetization curves of representative samples (representative samples: GXSS-9, JTL-28, BHDD-35). 

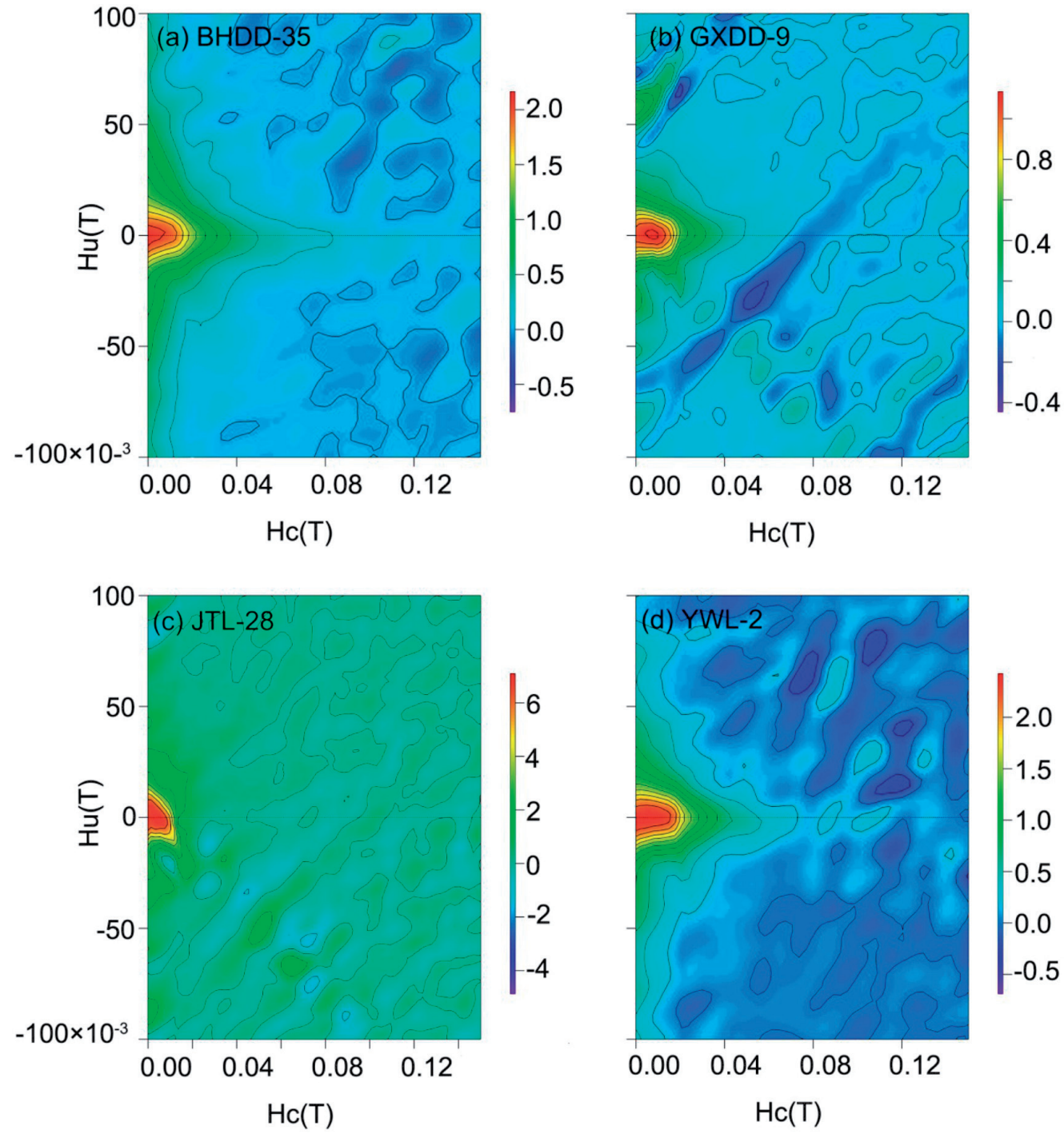

Fig. 3. FORC diagrams of representative soil samples of greenbelts in Baoji City.

refers to the reversal of the magnetic field strength required to reduce sample magnetization from saturation to 0 [38]. The coercivity remanence $\left(B_{\mathrm{cr}}\right)$ of magnetite was less than $50 \mathrm{mT}$ [32]. As shown in Fig. $2 \mathrm{~b})$, the coercivity remanence $\left(B_{\mathrm{cr}}\right)$ in samples was about $30 \mathrm{mT}$, which was much less than $50 \mathrm{mT}$, suggesting that the primary magnetic mineral contained in the sample was magnetite with low coercivity.

\section{Magnetic Mineral Particle Size}

The FORC diagram not only reveals the magnitude of coercivity of magnetic minerals and the interaction between magnetic mineral particles, but also distinguishes the types and magnetic domains of magnetic minerals [39]. The FORC chart (Fig. 3) of the representative sample has a large opening shape along the ordinate, and the central coercive force is relatively low, around $0.02 \mathrm{~T}$, indicating that the magnetic minerals contained in the samples were PSD and MD particles of magnetite [39].

\section{Heavy Metal Content}

As shown in Table 2, the average values of heavy metals in soil of the greenbelts were higher than the background values. The average values of $\mathrm{Cu}, \mathrm{Zn}$ and Pd were $44.38,168.42$ and $68.90 \mathrm{mg} / \mathrm{kg}$, respectively, which were 2.07, 2.43 and 3.22 times greater than the soil background value of Shaanxi Province. Cd was the metal present in the highest concentration, with an average value of $1.12 \mathrm{mg} / \mathrm{kg}$, which was about 11.9 times the background value and 3.7 times of the national secondary standard. The content of other heavy metals did not exceed the national secondary standard. These results indicated that the four heavy metals measured in the greenbelt soil of Baoji showed different degrees of accumulation. The maximum values of $\mathrm{Cu}$, $\mathrm{Zn}, \mathrm{Cd}$ and $\mathrm{Pd}$ were 2.87, 8.06, 34.02 and 6.46 times higher than the minimum values, respectively, indicating significant differences in the spatial accumulation of heavy metals. 
Table 2. Heavy metals content in greenbelts soil $(\mathrm{mg} / \mathrm{kg})$.

\begin{tabular}{|c|c|c|c|c|}
\hline & $\mathrm{Cu}$ & $\mathrm{Zn}$ & $\mathrm{Cd}$ & $\mathrm{Pb}$ \\
\hline Mean & 44.38 & 168.42 & 1.12 & 68.90 \\
\hline Max & 74.83 & 345.11 & 6.80 & 185.88 \\
\hline Min & 26.07 & 42.82 & 0.20 & 28.78 \\
\hline Background value of Shaanxi Province [40] & 21.40 & 69.40 & 0.09 & 21.40 \\
\hline National secondary standard [41] & 100,00 & 250.00 & 0.30 & 300.00 \\
\hline
\end{tabular}

\section{Soil Magnetic Characteristics}

The above analysis showed that the average value of $\mathrm{S}_{\text {-ratio }}$, isothermal remanent magnetization (IRM) curve and demagnetization curve of representative samples all revealed that the main magnetism bearing minerals in the soil samples of urban greenbelts of Baoji were ferrimagnetic materials with low coercivity (magnetite and maghemite), and that there were few incomplete antiferromagnetic minerals. Frequency susceptibility $\left(\chi_{\mathrm{fd}} \%\right)$ can indicate the contribution of superparamagnetic (SP) particles in a sample to the magnetic susceptibility [42]. The semi-quantitative model that estimated the concentration of crystal using $\chi_{\mathrm{fd} \%}$ showed that, for cases with $\chi_{\mathrm{fd} \%}<2 \%$, coarsegrained magnetic minerals were the main magnetic components, containing almost no SP particles. For cases with $\chi_{\mathrm{fd} \%}<5 \%$, coarse-grained particles were dominant components with a few SP particles, while for cases with $\chi_{\mathrm{fd} \%}>6 \%$, SP particles with a particle size of about $0.015 \mu \mathrm{m}$ increased notably and for cases with $\chi_{\mathrm{fd} \%}>10 \%$, SP crystals were the dominant components in the samples [43]. As shown in Table 1, the $\chi_{\mathrm{fd}} \%$ value of soil samples in the study area ranged from $0.94 \%$ to $7.58 \%$, with an average of $3.77 \%$, indicating that the soil samples contained mainly coarse and fine grains and almost no SP grains. Ratio of saturation remanence magnetization to magnetization strength $\left(M_{\mathrm{rs}} / M_{\mathrm{s}}\right)$ of the magnetic mineral and the ratio of remanence coercive

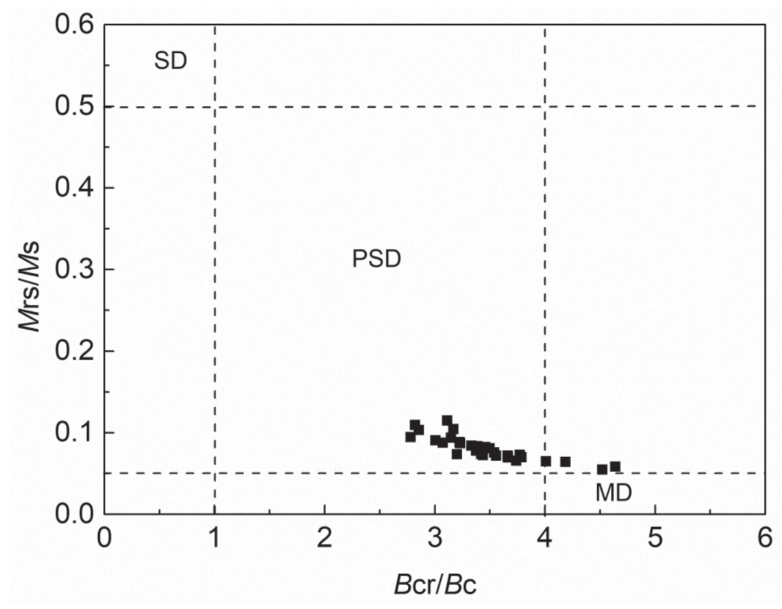

Fig. 4. Day diagrams of greenbelts soil in Baoji City. force to coercive force $\left(B_{c r} / B_{c}\right)$ was used to establish a Day diagram to ideally indicate the mineral particle size [44]. As shown in Fig. 4, most of the soil samples fell within the PSD section, with a few in the MD section, indicating that coarse particles such as MD and PSD were the main ferrimagnetic minerals in soil samples. These findings are consistent with the results shown in the FORC chart, indicating that the magnetic minerals in the soil of the greenbelt of Baoji are mainly dominated by coarse particles such as MD and PSD.

\section{Magnetic Response of Heavy Metal Pollution}

Previous studies have shown that the heavy metals $\mathrm{Zn}, \mathrm{Cu}, \mathrm{Cd}$ and $\mathrm{Pb}$ in the soil along the street are mainly from transportation emissions. $\mathrm{Cu}$ originates from the mechanical wear of brake pads, car brake systems and heat dissipation systems, while $\mathrm{Zn}$ comes from car tires and lubricating oil, Cd mainly originates from automobile exhaust, car tires and lubricating oil and $\mathrm{Pb}$ is produced by automobile exhaust, brake pads and car tires [45-47]. Metallurgical, steel, power generation and other industrial production processes also produce heavy metals such as $\mathrm{Zn}, \mathrm{Cu}, \mathrm{Cd}$ and $\mathrm{Pb}$, which release a number of magnetic particles during the discharge of heavy metal pollutants [28]. Therefore, there is a certain intrinsic link between magnetic minerals and some heavy metals in soil along the street in traffic. To further analyze the correlation between heavy metals and magnetic parameters of soil in the greenbelts of Baoji and better reveal the relationship between different parameters, four indicators of magnetic parameters $\left(\chi_{\mathrm{If}}\right.$ SIRM, SOFT and $\chi_{\mathrm{fd} \%}$ and four heavy metal element indicators $(\mathrm{Cu}, \mathrm{Zn}, \mathrm{Pb}$ and $\mathrm{Cd}$ ) were normalized for cluster analysis (Fig. 5). In the figure, smaller numbers along the $\mathrm{X}$-axis indicate high correlation. The distance between $\chi_{\mathrm{fd}} \%$ indicates the magnetic mineral particle size and heavy metals was 25 , indicating low correlation. Additionally, the values of the magnetic mineral content indexes SIRM, SOFT, and $\chi_{\text {If }}$ were close to the heavy metal elements $\mathrm{Pb}, \mathrm{Cu}$, $\mathrm{Zn}$ and $\mathrm{Cd}$ with a distance smaller than 10. In particular, the distance between $\mathrm{Pb}, \mathrm{Zn}$ and $\mathrm{Cu}$ and the index of magnetic mineral content was less than 5 , indicating a good correlation and thus a deep relationship between magnetic minerals with $\mathrm{Pb}, \mathrm{Cu}, \mathrm{Zn}$ and $\mathrm{Cd}$ in urban greenbelts soil of Baoji. 


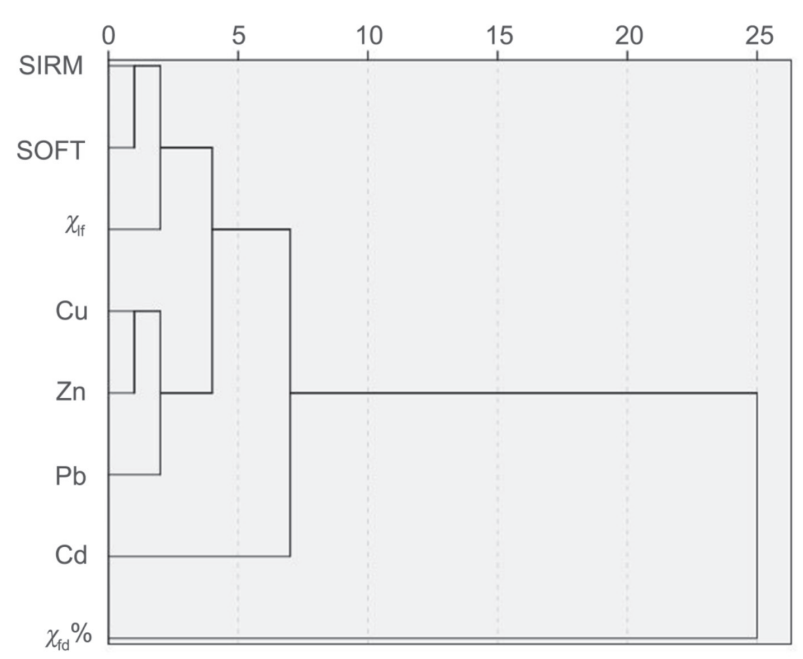

Fig. 5. Cluster analysis of greenbelts soil.

\section{Spatial Distribution of Magnetic Parameters and Pollution Load Index}

Calculation of the PLI value of each sample point showed that it ranged from 1.21 to 8.45 with a mean value of 3.14. Comparison of this result with the pollution load index evaluation scale table (Table 3) showed that the soil samples in the study area were of different pollution levels, and the high average values suggested heavy pollution.

The spatial distribution map of magnetic parameters $\chi_{\text {If }}$ SIRM and SOFT representing the magnetic mineral concentration and the pollution load index PLI representing the heavy metal pollution level were plotted (Fig. 6). As shown in Fig. 6a), Fig. 6b) and Fig. 6c), there was a large spatial difference in soil magnetic mineral content in greenbelts of Baoji. The overall pollution is higher in the west than in the east, and higher on the northern bank of the Weihe River than that the southern bank. High pollution areas were mainly located Region A (Jiangtan Road, Baofu Road) and B (Dongfeng Road and Daqing Road). Region A has contained a high concentration of industrial facilities since the 1950s and currently contains a pipe factory, machine factory, ceramics factory, power plant and other factories. Because of fossil fuel combustion, metal smelting, as well as particulate matter and tire wear debris emitted by large vehicles, the soil in the region, has a relatively high level of magnetic minerals. Region $\mathrm{B}$ is a prosperous area of Baoji. Because of an extension of the expressway, the daily traffic volume in this region is large. In addition, the Baoji freight station located in this area. As a result, there is a high level of pollution caused by large vehicles. PLI spatial distribution map as shown in Fig. 6d), the high value regions are consistent with regions with large traffic volume and concentrated factories, which is consistent with the distribution of $\chi_{\mathrm{If}}$, SOFT and SIRM. These results further demonstrate that the close relationship between magnetic mineral content and heavy metal content arise from urban transport, industrial production and fuel burning and/or other human activities. Magnetic parameters such as SIRM, SOFT and $\chi_{\text {If }}$ are effective indicators of heavy metals pollution of greenbelts soil.

In addition to the uneven distribution of traffic and factories, the spatial distribution of heavy metals in the soil along the street is also affected by greenbelt vegetation on both sides of the street. Studies have shown that bark and leaves of plants can effectively absorb and block atmospheric particulate matter [4851]. For greenbelt plants on both sides of the street, low and dense plant leaves can more effectively enrich the heavy metals emitted by vehicles. The greenbelt plants on both sides of region A are mostly deciduous trees, and the branches are too high from the ground. Only a small area is covered by shrubs and herbaceous plants under 1.5 meters. In this case, most particulate matter emitted by the vehicles is not absorbed by the leaves and shrubs and thus settles directly in the soil, resulting in serious heavy metals pollution. The greenbelt plants in region $\mathrm{C}$ include Pyramidalis, Prunus Cerasifera Ehrhar, Ligustrum vicaryi and Bauhinia as well as many other types of vegetation. The spatial composition of trees and shrubs in this region are scientifically designed. Previous studies showed that the leaves of plants in this area could block and adsorb particulate matter in air, and Ligustrum vicaryi showed the highest ability to retain particulate matter [52], resulting in soil with relatively low levels of heavy metals (Fig. 6). Therefore, during the construction of greenbelts, the absorption and retardation of atmospheric particulates by greenbelt plants should be fully considered. The composite structure of different types of vegetation is more conducive to the prevention and control of heavy metals deposition in soils caused by human activities.

\section{Magnetic Diagnosis of Heavy Metals Pollution in Soil of Urban Greenbelts of Baoji}

As stated above, magnetic minerals and heavy metals in the soil of urban greenbelts of Baoji are well correlated. Therefore, it is feasible to establish a magnetic diagnostic evaluation model of heavy metal

Table 3M The standard of pollution valueM

\begin{tabular}{|c|c|c|c|c|}
\hline PLI & $<1$ & $1 \sim 2$ & $2 \sim 3$ & $>3$ \\
\hline Pollution scale & 0 & I & II & III \\
\hline Pollution level & clean & slight pollution & moderate pollution & heavy pollution \\
\hline
\end{tabular}




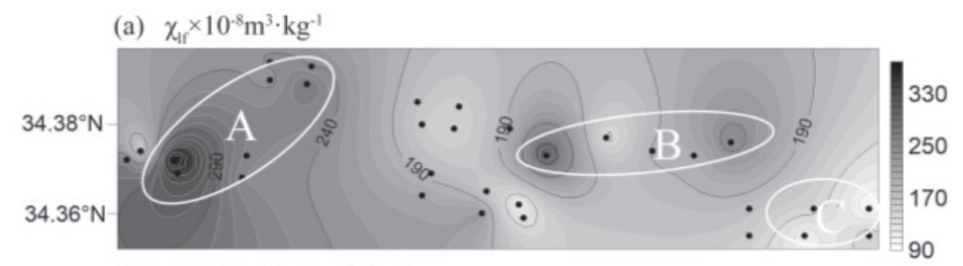

(b) $\operatorname{SIRM} \times 10^{-5} \mathrm{Am}^{2} \cdot \mathrm{kg}^{-1}$

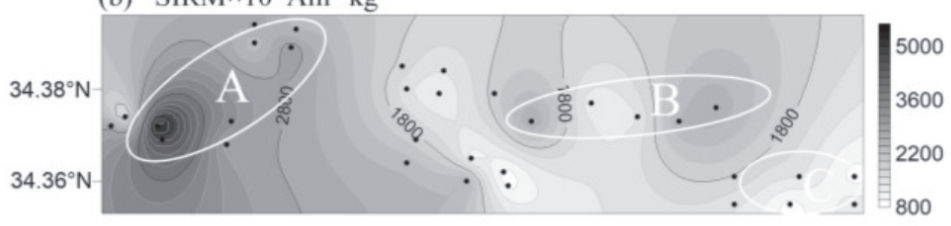

(c) SOFT $\times 10^{-5} \mathrm{Am}^{2} \cdot \mathrm{kg}^{-1}$

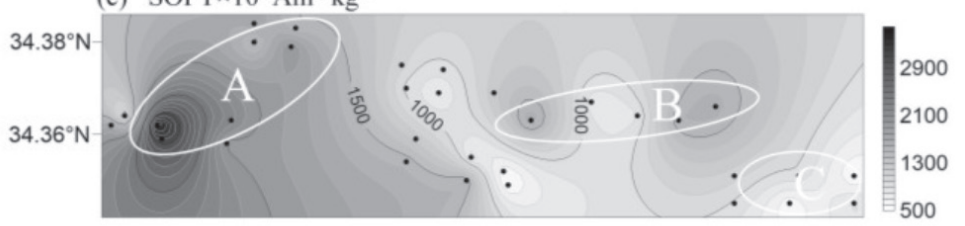

(d) PLI

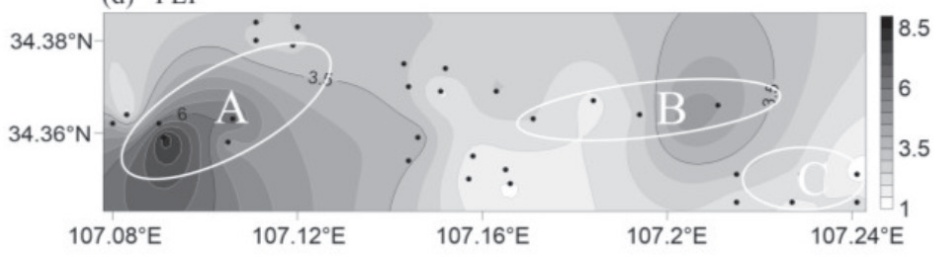

Fig. 6. Spatial variation of magnetic paremeters and PLI in greetbelts soil.

pollution of soil in greenbelts of Baoji using regression analysis of PLI representing heavy metal pollution and SIRM, SOFT and $\chi_{\text {If }}$ representing magnetic parameters (Table 4). As shown in Table 4, the correlation coefficient $\left(\mathrm{R}^{2}\right)$ between PLI and magnetic parameters is between 0.7 and 0.83 , indicating good correlation. Therefore, this magnetic diagnosis model is applicable to evaluation of the soil in greenbelts of Baoji.

According to the metal magnetic diagnosis model of greenbelt soils (Table 4), we obtained the magnetic diagnostic criteria of soil heavy metals in urban greenbelts of Baoji (Table 5). $\chi_{\text {If }}<74 \times 10^{-8} \mathrm{~m}^{3} / \mathrm{kg}$, SIRM $<342 \times 10^{-5} \mathrm{Am}^{2} / \mathrm{kg}$ and SOFT $<220 \times 10^{-5} \mathrm{Am}^{2} / \mathrm{kg}$ indicates that the soil is clean; $74 \times 10^{-8} \mathrm{~m}^{3} / \mathrm{kg} \leq \chi_{\text {If }}$ $<124 \times 10^{-8} \mathrm{~m}^{3} / \mathrm{kg}, 342 \times 10^{-5} \mathrm{Am}^{2} / \mathrm{kg} \leq \mathrm{SIRM}<1342 \times 10^{-5}$ $\mathrm{Am}^{2} / \mathrm{kg}$ and $220 \times 10^{-5} \mathrm{Am}^{2} / \mathrm{kg} \leq \mathrm{SOFT}<720 \times 10^{-5} \mathrm{Am}^{2} \mathrm{~kg}^{-1}$ indicates slight pollution; $124 \times 10^{-8} \mathrm{~m}^{3} / \mathrm{kg} \leq \chi_{\mathrm{If}}<$ $173 \times 10^{-8} \mathrm{~m}^{3} / \mathrm{kg}, 1342 \times 10^{-5} \mathrm{Am}^{2} / \mathrm{kg} \leq \mathrm{SIRM}<2342 \times 10^{-5}$ $\mathrm{Am}^{2} / \mathrm{kg}$ and $720 \times 10^{-5} \mathrm{Am}^{2} / \mathrm{kg} \leq \mathrm{SOFT}<1220 \times 10^{-5} \mathrm{Am}^{2} / \mathrm{kg}$ indicates moderate pollution; $\chi_{\mathrm{If}} \geq 173 \times 10^{-8} \mathrm{~m}^{3} / \mathrm{kg}$,

Table 4. Magnetic diagnostic model of heavy metals in greenbelt soil.

\begin{tabular}{|c|c|c|}
\hline Magnetic parameter & Diagnostic model & $\mathrm{R}^{2}$ \\
\hline$\chi_{\mathrm{If}}$ & PLI $=0.02 \chi_{\mathrm{If}}-0.472$ & 0.715 \\
\hline SIRM & PLI $=0.001 \mathrm{SIRM}+0.658$ & 0.806 \\
\hline SOFT & PLI $=0.002 \mathrm{SOFT}+0.561$ & 0.834 \\
\hline
\end{tabular}

Table 5. Magnetic diagnostic criteria for heavy metals in street greenbelt soil.

\begin{tabular}{|c|c|c|c|c|c|}
\hline $\begin{array}{c}\text { Pollution } \\
\text { scale }\end{array}$ & PLI & $\begin{array}{c}\text { Pollution } \\
\text { level }\end{array}$ & $\begin{array}{c}\chi_{\mathrm{lf}} \times 10^{-8} \\
/ \mathrm{m}^{3} / \mathrm{kg}\end{array}$ & $\begin{array}{c}\mathrm{SIRM} \times 10^{-5} \\
/ \mathrm{Am}^{2} / \mathrm{kg}\end{array}$ & $\begin{array}{c}\text { SOFT } \times 10^{-5} \\
/ \mathrm{Am}^{2} / \mathrm{kg}^{2}\end{array}$ \\
\hline 0 & PLI $<1$ & Clean & $\chi_{\mathrm{If}}<74$ & SIRM $<342$ & SOFT $<220$ \\
\hline I & $1 \leq \mathrm{PLI}<2$ & Slight pollution & $74 \leq \chi_{\mathrm{If}}<124$ & $342 \leq \mathrm{SIRM}<1342$ & $220 \leq \mathrm{SOFT}<720$ \\
\hline II & $2 \leq \mathrm{PLI}<3$ & Moderate pollution & $124 \leq \chi_{\mathrm{lf}}<173$ & $1342 \leq \mathrm{SIRM}<2342$ & $720 \leq \mathrm{SOFT}<1220$ \\
\hline III & PLI $\geq 3$ & Heavy pollution & $\chi_{\mathrm{If}} \geq 173$ & SIRM $\geq 2342$ & SOFT $\geq 1220$ \\
\hline
\end{tabular}


$\mathrm{SIRM} \geq 2342 \times 10^{-5} \mathrm{Am}^{2} / \mathrm{kg}$ and $\mathrm{SOFT} \geq 1220 \times 10^{-5}$ $\mathrm{Am}^{2} / \mathrm{kg}$ indicates heavy pollution.

A study of soil in Lanzhou showed that when there are different dominant pollution factors in the same batch of samples, the correlation between heavy metal elements and ferromagnetic mineral content is reduced and when using magnetic susceptibility as the reference parameter for urban heavy metal pollution, it is necessary to effectively distinguish samples of different types of pollution [22]. However, it is applicable to use magnetic parameters to monitor soil pollution levels of greenbelts of Baoji since this study focused on greenbelt soil and the main factor is traffic pollution with industrial pollution involved in a small area plus high $\mathrm{R}^{2}$ indicates good correlation. Magnetic parameters can be used as an effective indicator for monitoring the heavy metals pollution of soil in greenbelts.

\section{Conclusions}

(1) The content of magnetic mineral in the soil of greenbelts of Baoji is relatively high, and the main magnetic bearing mineral is a coarse-grained lowcoercivity ferrimagnetic mineral. Magnetic crystal grains are primarily coarse pseudo-domain and multi-domain, while also containing incomplete antiferromagnetic minerals. The spatial variation of magnetic mineral content is remarkable, with high levels observed in heavy traffic areas and industrial gathering areas, and low content in areas heavily covered by short vegetation.

(2) The heavy metals $\mathrm{Cu}, \mathrm{Zn}, \mathrm{Cd}$ and $\mathrm{Pb}$ in the soil of greenbelts of Baoji are higher than the background values. The average value of PLI is 3.14 , indicating heavy pollution of soil. The spatial distribution characteristics of PLI and magnetic parameters $\chi_{\mathrm{If}}$, SIRM and SOFT are almost the same, with pollution mainly originating from traffic and industry.

(3) Magnetic parameters such as $\chi_{\text {If }}$ SIRM and SOFT can be used as effective indicators for monitoring heavy metals pollution in soil of urban street greenbelts as follows: $\chi_{\text {If }}<74 \times 10^{-8} \mathrm{~m}^{3} / \mathrm{kg} \quad$ SIRM $<342$ $\times 10^{-5} \quad \mathrm{Am}^{2} / \mathrm{kg} \quad$ SOFT $<220 \times 10^{-5} \quad \mathrm{Am}^{2} / \mathrm{kg} \quad$ indicates clean soil; $74 \times 10^{-8} \mathrm{~m}^{3} / \mathrm{kg} \leq \chi_{\text {If }}<124 \times 10^{-8} \mathrm{~m}^{3} / \mathrm{kg} 342 \times 10^{-5}$ $\mathrm{Am}^{2} / \mathrm{kg} \leq \mathrm{SIRM}<1342 \times 10^{-5} \mathrm{Am}^{2} / \mathrm{kg}$ and $220 \times 10^{-5}$ $\mathrm{Am}^{2} / \mathrm{kg} \leq \mathrm{SOFT}<720 \times 10^{-5} \mathrm{Am}^{2} / \mathrm{kg}$ indicates moderate pollution of soil; $124 \times 10^{-8} \mathrm{~m}^{3} / \mathrm{kg} \leq \chi_{\mathrm{If}}<173 \times 10^{-8} \mathrm{~m}^{3} / \mathrm{kg}$, $1342 \times 10^{-5} \mathrm{Am}^{2} / \mathrm{kg} \leq \mathrm{SIRM}<2342 \times 10^{-5} \quad \mathrm{Am}^{2} / \mathrm{kg}$ and $720 \times 10^{-5} \mathrm{Am}^{2} / \mathrm{kg} \leq \mathrm{SOFT}<1220 \times 10^{-5} \mathrm{Am}^{2} / \mathrm{kg}$ indicates moderate-severe pollution; $\chi_{\mathrm{lf}} \geq 173 \times 10^{-8} \quad \mathrm{~m}^{3} / \mathrm{kg}$, SIRM $\geq 2342 \times 10^{-5} \mathrm{Am}^{2} / \mathrm{kg}$ and SOFT $\geq 1220 \times 10^{-5} \mathrm{Am}^{2} / \mathrm{kg}$ indicates heavy pollution.

\section{Acknowledgments}

This work was supported by the National Natural Science Foundation of China (Grant No. 41871147).

\section{Conflict of Interest}

The authors declare no conflict of interest.

\section{References}

1. WASEEM A., ARSHAD J., IQBAL F., SAJJAD A., MEHMOOD Z., MURTAZA G. Pollution status of pakistan: a retrospective review on heavy metal contamination of water, soil, and vegetables. BioMed Research International. 2014, 29, 2014.

2. AYDIN A., AKYOL E. Observing urban soil pollution using magnetic susceptibility. International Journal of Environmental Research. 9 (1), 295, 2015.

3. KOSHELEVA N.E., VLASOV D.V., KORLYAKOV I.D., KASIMOV N.S. Contamination of urban soils with heavy metals in Moscow as affected by building development. Science of the Total Environment. 636, 854, 2018.

4. CAO L.W., APPEL E., HU S.Y., YIN G., LIN H., ROSLER W. Magnetic response to air pollution recorded by soil and dust-loaded leaves in a changing industrial environment. Atmospheric Environment. 119 (12), 304, 2015.

5. CHOI J.Y., HONG G.H., RA K., KIM K., KIM K. Magnetic characteristics of sediment grains concurrently contaminated with TBT and metals near a shipyard in Busan, Korea. Marine Pollution Bulletin. 85 (2), 679, 2014.

6. WAWER M., MAGIERA T., OJHA G., APPEL E., KUSZA G., HU S.Y., BASAVAIAH N. Traffic-Related Pollutants in Roadside Soils of Different Countries in Europe and Asia. Water, Air, \&Amp; Soil Pollution. 226 (7), 2015.

7. DEARING J.A., LEES J.A., WHITE C. Mineral magnetic properties of acid gleyed soils under oak and Corsican Pine. Geoderma. 68 (4), 309, 1995.

8. GEISSMAN J. Environmental Magnetism: Principles and Applications of Enviromagnetics. Eos, Transactions American Geophysical Union. 85 (20), 2004.

9. TIWOW V.A., SUBAER, SULISTIAWATY, MALAGO J.D., RAMPE M.J., LAPA M. Magnetic susceptibility of surface sediment in the Tallo tributary of Makassar city. Journal of Physics: Conference Series. 1899 (1), 2021.

10. NARAYANA A.C., ISMAIEL M., PRIJU C.P. An environmental magnetic record of heavy metal pollution in Vembanad lagoon, southwest coast of India. Marine Pollution Bulletin. 167 (3-4), 2021.

11. LIANG X., YANG P.G., YAO J., ZHANG P., ZHANG J.H., SUN P.F., AO H. Environmental magnetic record of East Asian summer monsoon variability on the Chinese Loess Plateau since $16 \mathrm{kaBP}$. Geographical Science. 76 (03), 539, 2021

12. ATTOUCHEIK L., JORDANOVA N., BAYOU B., LAGROIX F., JORDANOVA D., MAOUCHE S., HENRY B., BOUTALEB A. Soil metal pollution from former $\mathrm{Zn}-\mathrm{Pb}$ mining assessed by geochemical and magnetic investigations: case study of the Bou Caid area. Environmental Earth Sciences. 76 (7), 298, 2017.

13. BOUHSANE N., BOUHLASSA S. Assessing magnetic susceptibility profiles of topsoils under different occupations. International Journal of Geophysics. 2018 (4), 1, 2018.

14. PAOLI L., WINKLER A., GUTTOVA A., SAGNOTTI L., GRASSI A., LACKOVICOVA A., SENKO D., LOPPI S. Magnetic properties and element concentrations in lichens exposed to airborne pollutants released during 
cement production. Environmental Science and Pollution Research. 24 (13), 1, 2017.

15. EL-HASAN T., LATAIFEH M. Field and dual magnetic susceptibility proxies for heavy metal pollution assessment in the urban soil of Al-Karak City, South Jordan. Environmental Earth Sciences. 69 (7), 2299, 2013.

16. VODYANITSKII Y.N., SAVICHEV A.T. Magnetite contamination of urban soils in European Russia. Annals of Agrarian Science. 15 (2), 155, 2017.

17. PETROVSKY E., KAPICKA A., JORDANOVA N. Magnetic properties of alluvial soils contaminated with lead, zinc and cadmium. Journal of Applied Geophysics. 48 (2), 127, 2001.

18. AYOUBI S., ADMAN V., YOUSEFIFARD M. Use of magnetic susceptibility to assess metals concentration in soils developed on a range of parent materials. Ecotoxicology and Environmental Safety. 168, 138, 2019.

19. ZONG Y.T., XIAO Q., LU S.G. Magnetic signature and source identification of heavy metal contamination in urban soils of steel industrial city, Northeast China. Journal of Soils \& Sediments. 17 (1), 190, 2017.

20. OUDEIKA M.S., ALTINOLU F.F., AKBAY F., AYDIN A. Heavy metal contamination of topsoil in Denizli Organized Industrial Zone, Western Anatolia, Turkey. Arabian Journal of Geosciences. 14 (8), 2021.

21. RACHWA M., WAWER M., MAGIERA T., STEINNES E. Integration of soil magnetometry and geochemistry for assessment of human health risk from metallurgical slag dumps. Environmental Science and Pollution Research. 24 (2), $1,2017$.

22. VODYANITSKII Y.N., SHOBA S.A. Magnetic susceptibility as an indicator of heavy metal contamination of urban soils (Review). Moscow University Soil Science Bulletin. 70 (1), 10, 2015.

23. SHI Y.H., LIU X.M., MAO X.G., Lu B., LIU G.Y., CHEN J.N. Study on environmental magnetic characteristics of loess in Har Keren Desert, Israel. Acta Pedologica Sinica. 57 (5), 1177, 2020.

24. KARIMI A., HAGHNIA G.H., AYOUBI S., SAFARI T. Impacts of geology and land use on magnetic susceptibility and selected heavy metals in surface soils of Mashhad plain, northeastern Iran. Journal of Applied Geophysics. 138, 127, 2017.

25. CHEN X.G., WEI J., SUN H.L., YANG H., LI, Y. Environmental magnetic properties and their spatial variability of topsoil in Urumqi City. Arid Land Geography. 37 (2), 265, 2014.

26. LIU D.X., MA J.H., SUN Y.L., LI Y.M. Spatial distribution of soil magnetic susceptibility and correlation with heavy metal pollution in Kaifeng City, China. Catena. 139, 53, 2016.

27. WANG G., CHEN Y.Y., XIA D.S., REN F.F., FANG A.D., MA L.J. Magnetic property of urban topsoil and its implication of heavy metal pollution in Shanghai. Acta Scientiae Circumstantiae. 38 (8), 3302, 2018.

28. WANG B., XIA D.S., YU Y., JIA J., XU S.J. Magnetic records of heavy metal pollution in urban topsoil in Lanzhou, China. Chinese Science Bulletin. 58 (3), 384, 2013.

29. CHEN Y.Y., WANG G., CHEN J., YU S.Y., REN F.F. Magnetic response of heavy metal pollution in urban topsoil of Yangpu District, Shanghai city. Bulletin of Soil and Water Conservation. 37 (03), 28, 2017.

30. 30. Golden, N., Zhang, C., Potito, A. P., Gibson, P. J., Bargary, N., Morrison, L. Impact of grass cover on the magnetic susceptibility measurements for assessing metal contamination in urban topsoil. Environmental Research. 155 (5), 294, 2017.

31. LE Z.J., CHEN J.S., LIU X.M., XIE Z.L., PENG C., LI P.Y. Isothermal Remanent Magnetization Acquisition Curves Reveal the Magnetic Susceptibility Variations Mechanism of the Siberian Loess. Journal of Fujian Normal University (Natural Science Edition). 35 (4), 93, 2019.

32. ZHANG X.F., LU B., CHEN Z.X., MA X.Y., ZHAO G.Y. A compareative analysis of magnetic properties of subtropical red soil derived from different weathering crusts. Chinese Journal of Geophysics. 62 (09), 3509, 2019.

33. ZENG Y.Y., ZHAO B. Paleoclimate implication of magnetic susceptibility in the loess-paleo soil will enlighten studying on the paleoclimate of the red soil in southern China. Progress in Geophysics. 35 (05), 1717, 2020.

34. LIU Q.S., ROBERTS A.P., LARRASOANA J.C., BANERJEE S.K., GUYODO Y., TAUXE L. Environmental magnetism: Principles and applications. Reviews of geophysics. 50 (4), 197, 2012.

35. ZENG M., SONG Y., LI Y., FU C., QIANG, X., CHANG H., ZHU L., ZHANG Z., CHENG L. The relationship between environmental factors and magnetic susceptibility in the Ili loess, Tianshan Mountains, Central Asia. Geological Journal. 54 (4), 1889, 2019.

36. LIU Q., JIN C., HU, P., JIANG Z., GE K., ROBERTS A.P. Magnetostratigraphy of Chinese loess-paleosol sequences. Earth-Science Reviews. 150, 139, 2015.

37. SUN H., SONG Y., YUE L.I., CHEN X., RUSTAM O. Magnetic susceptibility and grain size records of Bole loess section in the northern piedmont of Tianshan Mountains and their implications for paleoclimatic changes. Journal of Earth Environment, 2018.

38. ZHANG Y.L., LIU X.W., CHEN Q.M., YANG X Y., NAN Z.R. Comparative study of tessier method and modified BCR method for extracting $\mathrm{Cd}$ in loess amended by composted sludge. Environmental Engineering. 37 (05), 34, 2019.

39. YAMAZAKI T., WEI F., SHIMONO T., USUI Y. Unmixing biogenic and terrigenous magnetic mineral components in red clay of the pacific ocean using principal component analyses of first-order reversal curve diagrams and paleoenvironmental implications. Earth, Planets and Space. 72(1), 1-15, 2020

40. National Environmental Protection Agency, China National Environmental Monitoring Centre. Background values of soil elements in China. Beijing: China Environmental Science Press. 1990.

41. GB 1561-2008. Environmental quality standard for soils. 2008.

42. COELLIT. A multi-stage methodology for the solution of orientated DEA models. Operations Research Letters. 23 (3), 143, 1998.

43. CAVES R.E. Multinational Enterprise and Economic Analysis. Cambridge University Press. 1982.

44. LI X.W., ZHANG P., QIANG X.K., AO H. Rock magnetism study on loess-paleosol sequence at Huixinggou section of Sanmenxia Basin. Advances in Earth Science. 32 (05), $513,2017$.

45. SHAO L., XIAO H.Y., WU D.S., TANG C.G. Review on research on traffic-related heavy metals pollution. Earth and Environment. 40 (3), 445, 2012.

46. SOLTANI N., KESHAVARZI B., MOORE F., TAVAKOL T., LAHIJANZADEH A.R., JAAFARZADEH N., KERMANI M. Ecological and human health hazards 
of heavy metals and polycyclic aromatic hydrocarbons (PAHs) in road dust of Isfahan metropolis, Iran. Science of the Total Environment, 505 (6), 712, 2015.

47. ZHU M.J., TANG L., LIU D.Q. Monitor and risk assessment of heavy metals in the soils along the main road-a review. Environmental Monitoring in China. 31 (3), 84, 2015.

48. SALMOND J.A., TADAKI M., VARDOULAKIS S., ARBUTHNOTT K., COUTTS A., DEMUZERE M., DIRKS K.N., HEAVISIDE C., LIM S., MACINTYRE H., MCLNNES R.N., WHEELER B.W. Health and climate related ecosystem services provided by street trees in the urban environment. Environmental Health. 15 (1), S36, 2016.
49. ZHAO C.X., WANG Y.J., WANG Y.Q. Interactions between fine particulate matter $\left(\mathrm{PM}_{2.5}\right)$ and vegetation: a review. Chinese Journal of Ecology. 32 (8), 2203, 2013.

50. FAN S.X., CAI Y., DONG L. Dust absorption capacities of eight evergreen broad-leaved plants in Beijing, China. Chinese Journal of Applied Ecology. 28 (2), 408, 2017.

51. LIU F., CHU H.M., ZHENG X.M. Magnetic response of dust-loaded leaves in parks of Shanghai to atmospheric heavy metal pollution. Environmental Science. 36 (12), 4374, 2015.

52. ZHANG J.H., JIANG S., LIU B., WANG Y.H. Magnetic response of environmental pollution about different vegetation leaves in Binhe Street of Baoji City. China Environmental Science. 38 (5), 1893, 2018. 
